\title{
Dissociation between vasospasm and functional improvement in a murine model of subarachnoid hemorrhage
}

\author{
Rachel G. Mesis, B.S., Haichen Wang, M.D., Frederick W. Lombard, M.B.Ch.B., \\ Robert Yates, B.S., Michael P. Vitek, Ph.D., Cecil O. Borel, M.D., \\ DAVID S. WARNER, M.D., AND DANIEL T. LASKOWITZ, M.D.
}

\begin{abstract}
Multidisciplinary Neuroprotection Laboratories and the Departments of Medicine (Neurology), Neurobiology, and Anesthesiology, Duke University Medical Center and Duke University School of Medicine, Durham, North Carolina; University of Cincinnati School of Medicine, Cincinnati, Ohio; and Cognosci, Inc., Research Triangle Park, North Carolina
\end{abstract}

\begin{abstract}
Object. The efficacy of nimodipine was examined in a murine model of subarachnoid hemorrhage (SAH). End points included the diameter of the lumen of the middle cerebral artery (MCA) and behavioral outcome. An apolipoprotein E (apoE)-mimetic peptide, acetyl-AS-Aib-LRKL-Aib-KRLL-amide, previously shown to have promise in this model was tested both alone and in combination with nimodipine. The effects of carboxyamidotriazole (CAI), a non-voltage-gated calcium channel blocker, were explored using the same animal paradigm.

Methods. Experimental SAH was induced in male C57B1/6J mice. For 3 days postoperatively, behavioral analyses were performed. In the first experiment, the mice were treated with vehicle or with low- or high-dose CAI for 3 days. In the second experiment, the mice were treated with vehicle, high- and low-dose nimodipine, and/or the apoE-mimetic peptide. On postoperative Day 3 each mouse was killed and perfused. Following this, the right MCA was removed and its lumen measured.

Mice that received nimodipine demonstrated significant behavioral improvements when compared with vehicle-treated mice, but there was no clear dose-dependent effect on MCA diameter. Administration of the apoE-mimetic peptide was associated with improved functional performance and a significant reduction in vasospasm. Mice that received highdose CAI performed worse on functional tests, despite a significant increase in the diameters of their MCA lumina.

Conclusions. These results demonstrate a dissociation between vasospasm and neurological outcomes that is consistent with findings of previous clinical trials.
\end{abstract}

\section{KEY WORDS - subarachnoid hemorrhage - vasospasm • neuroprotection • nimodipine - apolipoprotein $\mathrm{E}$}

$\mathrm{A}$ MONG patients who suffer SAH and survive the initial ictus, vasospasm remains the most feared medical complication. Vasospasm is a frequent source of secondary stroke and the delayed ischemic deficits that usually develop within the first 2 weeks after hemorrhage. ${ }^{20}$ At present, there are significant limitations to the treatment of aneurysmal SAH-induced cerebral vasospasm. Current therapeutic options include intracranial angioplasty, triple- $\mathrm{H}$ (hypervolemia, hemodilution, and hypertension) therapy, and oral administration of nimodipine as vasospasm prophylaxis. However, because the majority of patients who suffer SAH either die or become permanently disabled, there is substantial room for improvement in treatment strategies for this group of patients. ${ }^{8}$

Abbreviations used in this paper: $\mathrm{ACA}=$ anterior cerebral artery; apoE = apolipoprotein $\mathrm{E} ; \mathrm{CA}=$ carotid artery; $\mathrm{CAI}=$ carboxyamidotriazole $; \mathrm{MCA}=$ middle cerebral artery; $\mathrm{SAH}=$ subarachnoid hemorrhage.
Nimodipine was introduced as a therapeutic agent for the prophylaxis of vasospasm based on findings of a small randomized clinical trial in the US ${ }^{1}$ and a large trial in the United Kingdom. ${ }^{24}$ Both trials revealed modest improvements in neurological outcomes following nimodipine administration. Athough the drug is accepted as the standard of care, the mechanism by which it works remains controversial. In addition to causing vascular relaxation, nimodipine may also serve as a neuroprotectant by blocking early neuronal calcium influx in the setting of acute ischemia. ${ }^{9} 10$ In fact, despite an improvement in functional outcome, no difference in angiographic vasospasm was observed between treatment and placebo in several trials. ${ }^{1,23,24}$ This is in contrast to the results of recent studies involving nicardipine, a similar dihydropyridine voltagegated calcium channel blocker, which demonstrated improvements in angiographic vasospasm but no improvement in functional outcomes. ${ }^{6,7}$ The dissociation between angiographically confirmed vasospasm and functional improvement calls into question whether the effects 
of these calcium channel blockers are due to other mechanisms in addition to vasodilation, and whether surrogate radiographic evidence of vasospasm is appropriate as the sole clinical end point in early clinical trials.

Given our limited understanding of the pathophysiology of vasospasm and the pressing clinical need for more effective approaches, the use of clinically relevant animal models of SAH remains extremely important. A variety of animal models have been developed. Nosko and colleagues ${ }^{21}$ studied the effects of nimodipine on chronic vasospasm in monkeys and, using their model, produced results similar to those found in clinical trials. No difference in the incidence and severity of delayed vasospasm in a rabbit model was attributed to the use of nimodipine in a study in which dynamic perfusion computed tomography imaging was used. ${ }^{13}$ In both animal studies angiographically determined end points were used and the conclusions were similar to those of human clinical trials; however, neither study incorporated the behavioral outcomes of the animals, a limitation found in many studies involving animal models of SAH.

Recently, a murine model of SAH has been characterized that demonstrates evidence of vascular proliferation, lumen narrowing, and functional impairments. ${ }^{22}$ The clinical relevance of this model in testing new therapeutic approaches was suggested by the finding that the protective effects of simvastatin on murine vasospasm were readily translatable to the clinical arena. ${ }^{16,18}$ One advantage of using a murine model is the availability of transgenic technology that can be used to differentiate the molecular mechanisms of disease. For example, recent studies involving endothelial nitric oxide synthase knockout transgenic animals demonstrated that the palliative effects of statins in the presence of SAH were dependent on upregulation of endothelial nitric oxide synthase. ${ }^{19}$

Transgenic mice have also been used to study the role of genetic polymorphisms in recovery from neurological disease. For example, several recent clinical observations have associated the apoE isoform with outcomes after acute brain injury., ${ }^{4,27}$ Specifically, the presence of the apoE4 isoform is associated with increased incidences of vasospasm and worse outcome after aneurysmal SAH. ${ }^{11,14}$ These observations were replicated in a murine SAH model and led to the development of an apoE-based therapeutic intervention that improved histological and functional outcome..$^{5,12}$

As nimodipine is currently given as the standard drug of choice in patients with aneurysmal SAH, any new prospective therapy should be expected to provide additional benefit. To optimize the clinical relevance of our model, we sought to demonstrate whether nimodipine improved functional and histological outcomes after SAH and whether the apoE-derived therapeutic peptide provided additional benefit over nimodipine alone. We also attempted to characterize the relative importance of vascular and neuroprotective effects by using CAI as a therapeutic intervention. Unlike nimodipine, CAI acts on non-voltage-gated calcium channels. This action would be expected to cause vasodilation in the absence of any direct neuronal effects. Carboxyamidotriazole also blocks the vascular endothelial growth factor signaling cascade and has been studied as a potential oncological drug and as a treatment for retinopathy associated with prematurity. ${ }^{2,3} \mathrm{~A}$ lack of improvement in neurological outcome observed in the presence of an increased diameter of the MCA lumen would strengthen the hypothesis that direct neuroprotection is a relevant mechanism by which dihydropyridine calcium channel blockers improve neurological outcome after SAH.

\section{Materials and Methods}

\section{Therapeutic Agents}

Nimodipine was obtained from the Duke University Medical Center Pharmacy in $30-\mathrm{mg} / \mathrm{ml}$ capsules. Each capsule was opened and the contents were diluted with $0.9 \% \mathrm{NaCl}$ until the desired concentrations $(0.67 \mathrm{mg} / \mathrm{ml}$ and $0.33 \mathrm{mg} / \mathrm{ml}$ ) were reached. The solutions were stored in a dark area in accordance with manufacturer recommendations. The CAI was obtained with permission from the National Institutes of Health. It was dissolved in polyethylene glycol and diluted to appropriate concentrations $(2.08 \mathrm{mg} / \mathrm{ml}$ and $0.83 \mathrm{mg} / \mathrm{ml})$. The solutions were refrigerated at $4^{\circ} \mathrm{C}$. The $1410-\mathrm{D}$ apoE-derived peptide, acetylAS-Aib-LRKL-Aib-KRLL-amide, was synthesized in the Peptide Synthesis Laboratory at the University of North Carolina (Chapel Hill, NC) to a purity of $95 \%$ and diluted in isotonic saline as previously described. ${ }^{5,12}$

\section{Murine Model of SAH}

Subarachnoid hemorrhage was produced using the method previously described by Parra, et al. ${ }^{22}$ Male C57B1/6J mice, 12 to 14 weeks of age, were placed in a chamber and anesthetized by administering a gas mixture containing isoflurane. The trachea was intubated and the lungs mechanically ventilated with a mixture of $1.6 \%$ isoflurane in $30 \%$ $\mathrm{O}_{2}$ /balance $\mathrm{N}_{2}$. A midline incision was made in the neck, and the right common CA was exposed. The external CA was then exposed and ligated, leaving a small stump attached to the common CA. A blunted 5-0 monofilament nylon suture, $10 \mathrm{~mm}$ in length, was introduced into the external CA stump and advanced into the internal CA to a point just distal to the bifurcation of the ACA and MCA in the circle of Willis. Here resistance was encountered and the suture was advanced $3 \mathrm{~mm}$ further to perforate the right ACA, resulting in subarachnoid bleeding. The suture was removed, hemostasis was ensured, and the skin was closed.

For the CAI experiment, the mice were randomly assigned to one of three groups: high-dose CAI (250 $\mathrm{mg} / \mathrm{kg} /$ day), low-dose CAI (100 mg/kg/day), or vehicle treatment. The CAI was administered by oral gavage immediately postoperatively and every 8 hours thereafter until postoperative Day 3. In the combined nimodipine-apoE peptide experiment, the mice were randomized to five groups: high-dose nimodipine $(8 \mathrm{mg} / \mathrm{kg} /$ day $)$, lowdose nimodipine $(4 \mathrm{mg} / \mathrm{kg} / \mathrm{day})$, high-dose nimodipine plus apoE-mimetic peptide $(1.2 \mathrm{mg} / \mathrm{kg} /$ day $)$, the peptide alone $(1.2 \mathrm{mg} / \mathrm{kg} / \mathrm{day})$, or vehicle treatment. The peptide dose was selected based on the optimum dose determined in a previous study, ${ }^{5}$ whereas the two nimodipine doses were chosen based on standard dosages used in clinical practice. The apoE-mimetic peptide was given intravenously immediately postoperatively and every 12 hours 

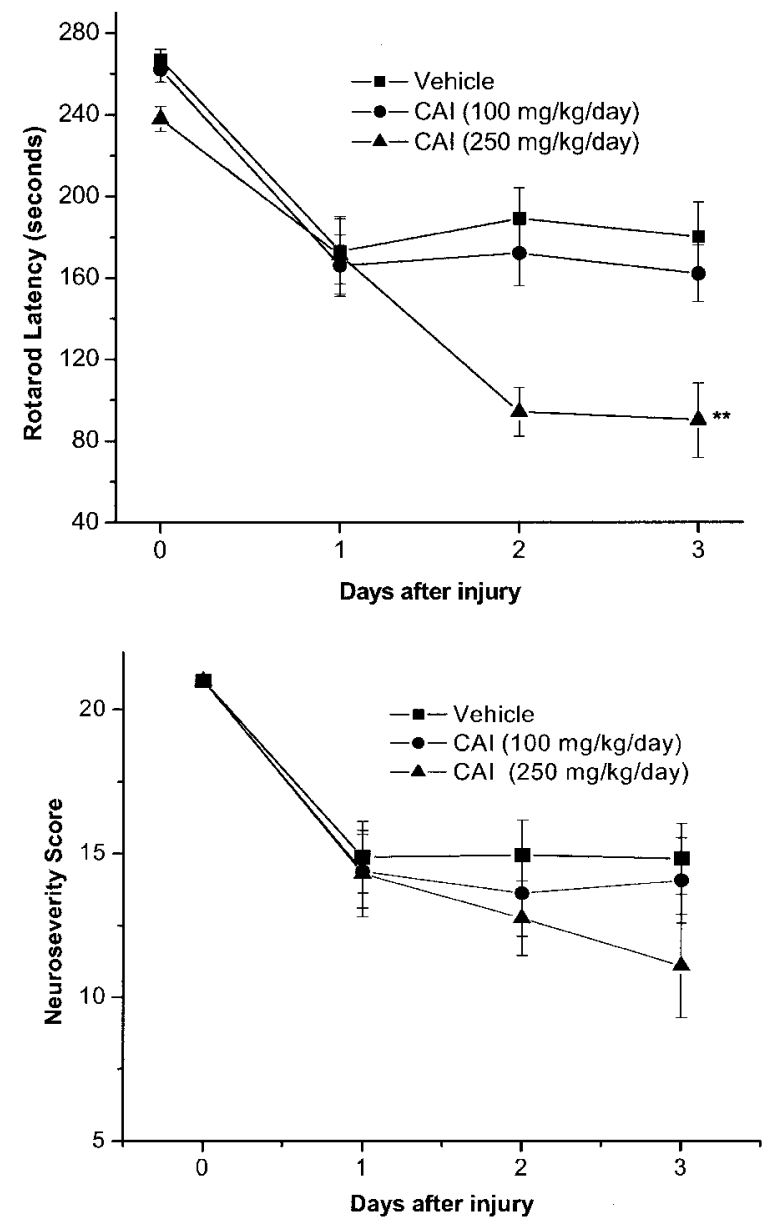

FIG. 1. Line graphs demonstrating the effects of CAI on rotarod latency and neurological severity scores. Administration of CAI at a dose of $250 \mathrm{mg} / \mathrm{kg} /$ day results in significantly worse functional performance on the rotarod (upper) and a lower average neurological severity score (lower) than found in the vehicle-treated group. In the latter case, however, this difference did not reach statistical significance. $* * \mathrm{p}<0.001$.

thereafter until the mice were killed on postoperative Day 3 . Nimodipine was given via oral gavage immediately postoperatively and every 8 hours thereafter. Behavioral analysis was conducted by performing a rotarod test, and a neurological severity score was assigned to each animal every day. After the behavioral assessment had been made on Day 3, the mouse was killed and its vasculature was perfused with an India ink-gelatin mixture. The dead animal was refrigerated for 24 hours, after which its brain was removed and the diameter of the right MCA was measured.

\section{Neurological Evaluation Following SAH}

Behavioral outcomes were assessed by an observer blinded to animal group assignment who used a neurological severity scale ${ }^{26}$ (score range 3-21) and rotarod testing. ${ }^{15}$ On the day before surgery, baseline rotarod data and

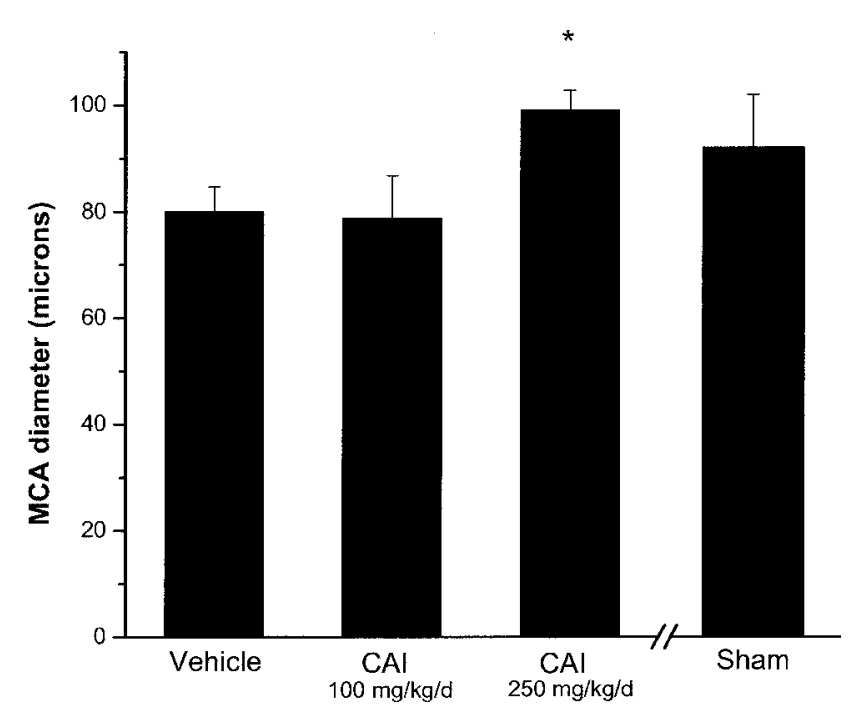

FIG. 2. Bar graph showing that administration of high-dose CAI causes a significant increase in the MCA lumen diameter compared with vehicle treatment. The inclusion of data for sham-operated animals is for illustrative purposes only; this group was not included in the statistical analysis. ${ }^{*} \mathrm{p}<0.05$.

neurological severity scores were obtained for all mice. The rotarod data were collected by first placing the mice on the apparatus (Ugo Basile, Comerio, Italy) for a 300second training period with the rotarod set in the accelerating rotational speed mode. Afterward, using this accelerating rotational speed mode, rotarod latencies were recorded for three trials per mouse. A neurological severity score was then assigned. The score was based on an assessment of motor components derived from spontaneous activity, symmetry of limb movements, climbing, and balance and coordination, with each component being scored from 0 to 3 . Sensory components were used to analyze body proprioception and tactile and vibrissa responses to stimuli. These components were scored from 1 to 3. Assignment of the neurological severity score and the rotarod analysis (minus the initial training portion) were repeated daily for 3 days postoperatively.

\section{Blood Pressure Measurements}

Blood pressure was measured over a 120-minute period after administration of each drug or drug combination, in a separate animal cohort. Following administration of the drug(s), the mouse underwent tracheal intubation and anesthesia was induced using an isoflurane mixture. The femoral artery was cannulated via a small incision in the right groin. Blood pressure measurements were recorded every minute for the first 10 minutes and then every 5 minutes for the remaining 110 minutes.

\section{Cerebral Vascular Perfusion and MCA Diameter After SAH}

After the behavioral examination had been completed on postoperative Day 3, cerebral vascular perfusion was performed as described previously. ${ }^{5,22}$ Each mouse was placed in a chamber and isoflurane was administered to induce anesthesia. The animal's trachea was intubated and 
its chest opened to allow cannulation of the proximal aorta. Plastic tubing (3.22-mm internal diameter) was used to deliver infusion solutions in a pulsatile manner. ${ }^{18,22}$ Thirty milliliters of $0.9 \% \mathrm{NaCl}, 20 \mathrm{ml}$ of $10 \%$ formalin, and 10 $\mathrm{ml}$ of India ink-gelatin mixture were infused in that order. The dead mouse was refrigerated for 24 hours to ensure solidification of the gelatin within the vasculature. Following refrigeration, the mouse brain was harvested and stored in $10 \%$ formalin. The cerebral vasculature was photographed using a video-linked dissecting microscope controlled by an image analyzer (MCID Elite; Interfocus Imaging, Linton, United Kingdom). The diameter of the right MCA at the site $1 \mathrm{~mm}$ distal to the MCA-ACA bifurcation was recorded using digital measurement techniques.

\section{Statistical Analysis}

Rotarod latencies and neurological severity scores were compared using repeated-measures analysis of variance with time as the repeated variable. When the resulting $\mathrm{F}$ values were greater than 1 , the Student t-test was used to compare drug-treated groups with the vehicle-treated group. The diameters of the MCA lumina were also compared using the unpaired Student t-test.

\section{Results}

\section{Hemodynamic Effects of Therapy}

Given the vasoactive nature of the drugs used and the potential confounding effects of hypotension, the hemodynamic effects of high-dose CAI, nimodipine, and apoEmimetic peptide were tested in surrogate animals. No significant changes were observed after administration of any of these drugs or drug combinations.

\section{Effect of CAI on SAH Outcome}

To test the effect of CAI as a possible therapy to reduce vasospasm, we administered vehicle (16 animals), lowdose CAI (100 mg/kg/day; 16 animals), or high-dose CAI $(250 \mathrm{mg} / \mathrm{kg} / \mathrm{day} ; 12$ animals) after induction of SAH. A significant decrease in rotarod latency (that is, the time the animal remains on the rotating bar) was observed following administration of high-dose CAI compared with administration of vehicle (mean latency for animals receiving high-dose CAI $90 \pm 18$ seconds; mean latency for animals receiving vehicle $180 \pm 17$ seconds; $p=0.0008$ ) (Fig. 1A). The neurological severity scores paralleled the results of the rotarod tests (Fig. 1B).

The diameters of the right MCA lumina are summarized in Fig. 2. A significant increase in MCA diameters was observed when the high-dose CAI-treated group (mean diameter $99 \pm 4 \mu \mathrm{m}$ ) was compared with the vehicle-treated group (mean diameter $80 \pm 4 \mu \mathrm{m} ; \mathrm{p}=0.0191$ ).

\section{Effects of Nimodipine on SAH Outcome}

In this experiment, mice were treated with vehicle (11 animals), low-dose nimodipine (4 mg/kg/day; 11 animals), or high-dose nimodipine ( $8 \mathrm{mg} / \mathrm{kg} /$ day; 11 animals $)$ after induction of SAH.

Rotarod latencies for both the high-dose nimodipinetreated group (mean latency $231 \pm 15$ seconds) and the low-dose nimodipine-treated group (mean latency $213 \pm$ 13 seconds) were significantly higher than those of the vehicle-treated group (mean latency $124 \pm 16$ seconds; $p<0.0001$ and $p=0.0068$, respectively). Significant differences in neurological severity scores were also observed between the treatment groups (mean score in the high-dose nimodipine-treated group was $17 \pm 1$ and that in the low-dose nimodipine-treated group was $18 \pm 1$ ) and the vehicle-treated group (mean score $12 \pm 2 ; \mathrm{p}<$ 0.05; Fig. 3).

Although both doses of nimodipine significantly improved behavioral outcomes, a significant improvement in MCA diameters was only identified in the group treated by the low dose. The mean diameter in the low-dose nimodipine-treated group was $91 \pm 5 \mu \mathrm{m}$ and that in the vehicle-treated group was $74 \pm 5 \mu \mathrm{m}(\mathrm{p}=0.034)$. The mean diameter in the high-dose nimodipine group was $89 \pm 7$ $\mu \mathrm{m}$ (Fig. 4).

\section{Effect of apoE-Mimetic Peptide on SAH Outcome}

The next goal of this study was to examine the effects of administration of apoE-mimetic peptide in our model. Based on previous studies, the optimum dose of the peptide has already been determined in this model, ${ }^{21}$ and thus only two groups of animals were used, mice treated with vehicle (11 animals) and those treated with peptide (1.2 $\mathrm{mg} / \mathrm{kg} /$ day; 11 animals). The peptide-treated group performed significantly better than the vehicle-treated group on the rotarod test and on tests of neurological severity ( $p$ $<0.001$ and $p=0.0040$, respectively; Fig. 3). In addition to improvements in behavioral outcomes, there was a significant increase in the diameters of the right MCA lumina in the peptide-treated group (mean diameter $97 \pm 6$ $\mu \mathrm{m})$ compared with the vehicle-treated group (mean diameter $74 \pm 5 \mu \mathrm{m} ; \mathrm{p}=0.02$; Fig. 4).

\section{Effect of Nimodipine Plus apoE-Mimetic Peptide on SAH Outcome}

Because nimodipine is currently used to treat SAH patients, we believe it is important to characterize the interactions between nimodipine and any new therapeutic agent, as any new treatment will probably be administered in combination with nimodipine in the clinical setting. For this portion of the experiment we compared two groups: one treated with vehicle (11 animals) and the other treated with both nimodipine and peptide (nimodipine $8 \mathrm{mg} / \mathrm{kg} /$ day, peptide $1.2 \mathrm{mg} / \mathrm{kg} /$ day; 11 animals). This combined treatment significantly improved both rotarod latency (229 \pm 16 seconds) and the neurological severity score $(17 \pm 1)$ compared with vehicle treatment $(\mathrm{p}<0.0001$ and $p=0.0216$, respectively; Fig. 3 ). The behavioral outcomes in this combination group were not significantly different from those observed in the other treatment groups. In addition, a significant difference was not present between the diameters of the MCA lumina in the two groups (Fig. 4).

\section{Discussion}

In this article, we demonstrate that clinically relevant doses of nimodipine improved behavioral outcomes in 
this mouse SAH model without causing any dose-dependent change in the diameters of the MCA lumina. In contrast, the apoE-mimetic peptide improved behavioral outcomes and increased the diameters of the MCA lumina when compared with vehicle. Finally, high-dose CAI worsened functional outcomes, although it increased the diameters of the MCA lumina.
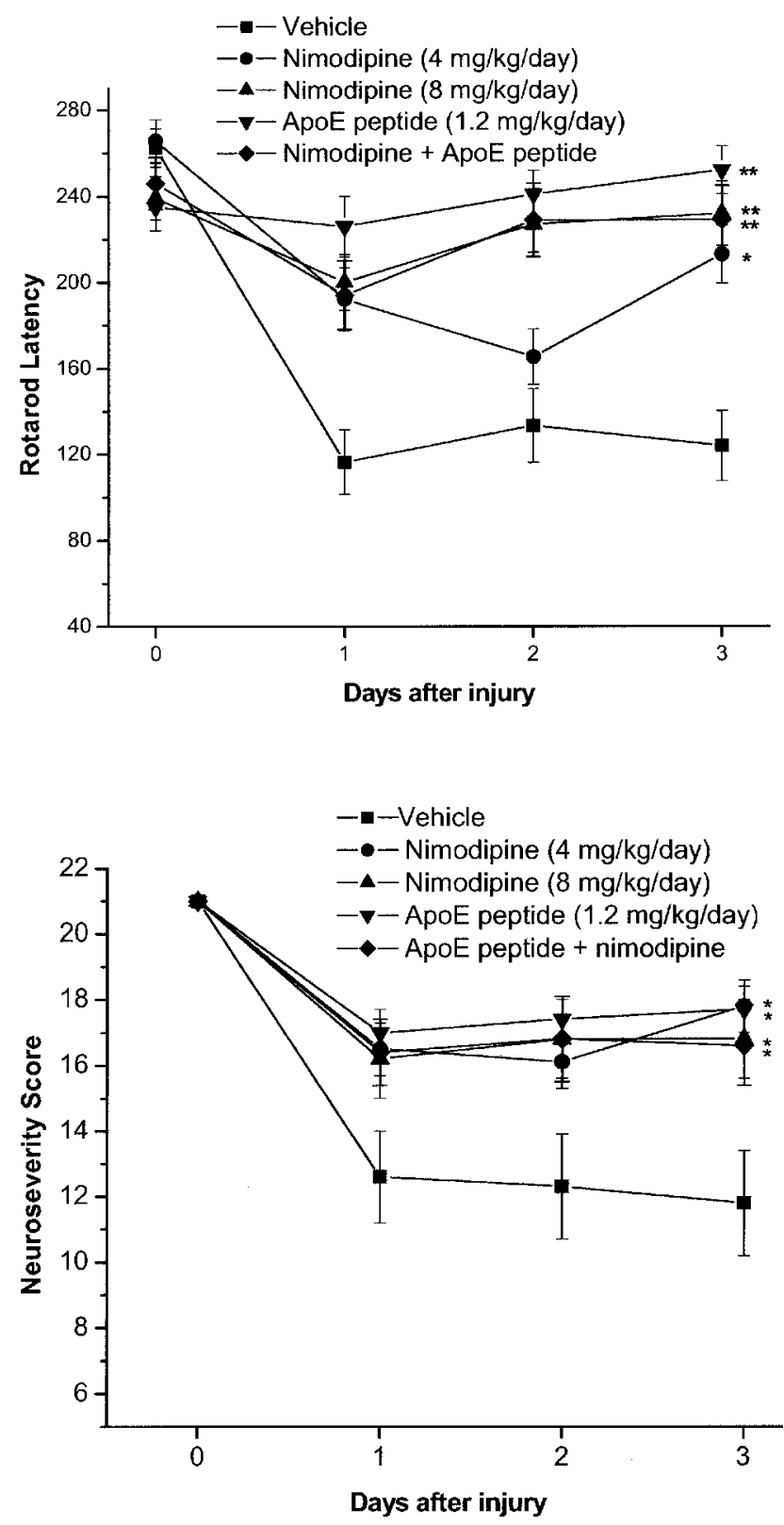

FIG. 3. Line graphs showing the effects of drugs on rotarod latency and neurological severity scores. Upper: An assessment of rotarod latencies after SAH shows significant improvements in drug-treated animals compared with vehicle-treated animals. Lower: Groups of animals treated with high-dose nimodipine (8 $\mathrm{mg} / \mathrm{kg} /$ day), low-dose nimodipine ( $4 \mathrm{mg} / \mathrm{kg} /$ day), apoE-mimetic peptide, and the combination of nimodipine and peptide had significantly improved neurological severity scores compared with the vehicle-treated group. ${ }^{*} \mathrm{p}<0.05 ; * * \mathrm{p}<0.01$.

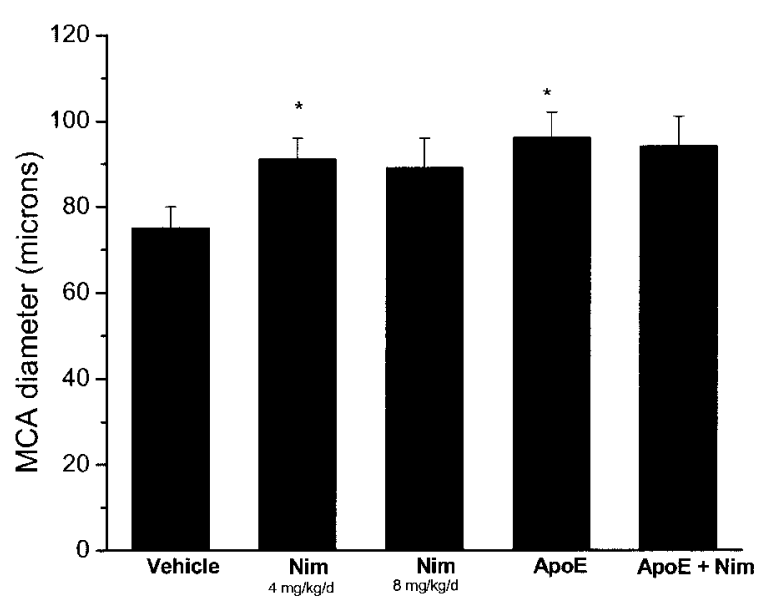

FIG. 4. Bar graphs demonstrating differences in the diameters of the MCA lumina. In a comparison of the four drug treatment groups with the vehicle-treated group in the nimodipine/apoEmimetic peptide experiment, only the low-dose nimodipine- and the peptide-treated groups had increased MCA diameters. $* \mathrm{p}<$ 0.05 .

Although nimodipine treatment is the standard of care in clinical practice following aneurysmal $\mathrm{SAH}$, its efficacy has been studied in relatively few animal models of SAH. ${ }^{13,21}$ In general, investigators have evaluated angiographic vasospasm rather than behavioral outcome. To increase the clinical relevance of our murine SAH model, we incorporated two end points: angiographic findings and behavioral outcomes. Although both low- and highdose nimodipine treatment improved behavioral outcome, only the low dose of the drug was associated with a significant reduction in vasospasm. This is consistent with the results of clinical studies of nimodipine in patients with $\mathrm{SAH}$, which have failed to demonstrate a consistent reduction in angiographically determined vasospasm despite improved functional outcome. . $^{1,23,24}$ This dissociation between improved lumen diameter and functional outcome suggests that, in addition to its vasoactive effects, nimodipine may be directly neuroprotective via its effect on voltage-gated neuronal calcium channels.

To explore this possibility further, we treated animals with CAI, which acts solely on non-voltage-gated calcium channels. Although CAI would be expected to have comparable vasodilatory effects on cerebral vessels, it would not be expected to have any direct effect on neuronal calcium channels. We demonstrated that, although treatment with CAI significantly enlarged the MCA lumen without hemodynamic compromise, the drug was associated with worse functional outcome than vehicle alone.

These results suggest that nimodipine may be acting at the neuronal level to block calcium influx. In fact, there is preclinical evidence suggesting that nimodipine is effective in instances of acute cerebral ischemia. ${ }^{9}, 10$ It is possible that the failure of nimodipine to improve stroke outcome in clinical trials is related to the delayed onset of drug administration in the clinical setting. Nevertheless, aneurysmal SAH represents a unique opportunity to initiate neuroprotective treatment before the onset of ischemia, 
which most often occurs within the first several weeks posthemorrhage. This delayed ischemia creates a window of opportunity during which neuroprotective interventions can be prophylactically administered.

Our results suggest a dissociation between changes in the diameter of the MCA lumen and functional improvement, and this is consistent with the findings of several clinical trials. ${ }^{1,67,24}$ The possibility that surrogate radiographic evidence of vasospasm may not be predictive of functional outcome should be considered in the design of clinical trials in which new therapies for SAH are evaluated.

It is likely that genetic influences play an important role in recovery from acute brain injury., ${ }^{4,1725}$ Recent clinical observations suggest that apoE polymorphisms are associated with both the incidence of vasospasm and functional outcome after SAH. ${ }^{11,14}$ This genetic association led to the development of a novel therapeutic strategy involving the use of apoE-mimetic peptides derived from the receptorbinding region of apoE..$^{5,12,13}$ The results of our study confirm that intravenous administration of the apoE-mimetic peptide was well tolerated, improved functional outcomes, and reduced evidence of vasospasm following SAH. They also demonstrated that the apoE peptide was well tolerated when coadministered with nimodipine, and was at least as effective as nimodipine alone.

It is important to recognize the limitations of our model at this point. Following treatment, animals receiving SAH performed nearly as well as sham controls in our behavioral tests of rotarod latency and clinical neurological severity. This ceiling effect precluded any possible additive benefit of the apoE-nimodipine combination over nimodipine alone. Given that long-term neurocognitive deficits are common in patients with $\mathrm{SAH}$, incorporating longer-term tasks of learning and memory might improve the utility of this model.

\section{Conclusions}

We treated mice subjected to SAH with three different compounds known to have three distinct mechanisms of action. Outcome was based on the diameter of the MCA lumen and the results of behavioral/motor testing. All drugs investigated had an effect on outcome; however, there was no consistent relationship between the drugs' effects on the MCA diameter and improvements in motor/behavioral function. These data confirm the results of studies performed in SAH patients, in which a similar dissociation was identified between the morphological characteristics of vessels and neuronal function. The results also demonstrate the importance of including neurological function as an essential outcome measure of efficacy for drugs examined as potential therapeutic agents for vasospasm.

\section{References}

1. Allen GS, Ahn HS, Preziosi TJ, Battye R, Boone SC, Chou SN, et al: Cerebral arterial vasospasm-a controlled trial of nimodipine in patients with subarachnoid hemorrhage. N Engl J Med 308:619-624, 1983

2. Bauer KS, Figg WD, Hamilton JM, Jones EC, Premkumar A, Steinberg SM, et al: A pharmokinetically guided Phase II study of carboxyamido-triazole in androgen-independent prostate cancer. Clin Cancer Res 5:2324-2329, 1999
3. Franklin AJ, Jetton TL, Kuchemann CL, Russell SR, Cohn EC: CAI is a potent inhibitor of neovascularization and imparts neuroprotection in a mouse model of ischemic retinopathy. Invest Ophthalmol Vis Sci 45:3756-3766, 2004

4. Friedman G, Froom P, Sazbon L, Grinblatt I, Shochina M, Tsenter J, et al: Apolipoprotein E- $\epsilon 4$ genotype predicts poor outcome in survivors of traumatic brain injury. Neurology 52:244-247, 1999

5. Gao J, Wang H, Sheng H, Lynch JR, Warner DS, Durham L, et al: A novel apoE-derived therapeutic reduces vasospasm and improves outcome in a murine model of subarachnoid hemorrhage. Neurocrit Care 4:25-31, 2006

6. Haley EC Jr, Kassell NF, Torner JC: A randomized controlled trial of high dose intravenous nicardipine in aneurysmal subarachnoid hemorrhage. A report of the Cooperative Aneurysm Study. J Neurosurg 78:537-547, 1993

7. Haley EC Jr, Kassell NF, Torner JC: A randomized trial of nicardipine in subarachnoid hemorrhage: angiographic and transcranial Doppler ultrasound results. A report of the Cooperative Aneurysm Study. J Neurosurg 78:548-553, 1993

8. Hanel RA, Xavier AR, Mohammad Y, Kirmani JF, Yahia AM, Qureshi AI: Outcome following intracerebral hemorrhage and subarachnoid hemorrhage. Neurol Res 24 (Suppl 1): S58-S62, 2002

9. Inzitari D, Poggesi A: Calcium channel blockers and stroke. Aging Clin Exp Res (4 Suppl):16-30, 2005

10. Korenkov AI, Pahnke J, Frei K, Warzok R, Schroeder HWS, Frick R, et al: Treatment with nimodipine or mannitol reduces programmed cell death and infarct size following focal cerebral ischemia. Neurosurg Rev 23:145-150, 2000

11. Lanterna LA, Rigoldi M, Tredici G, Biroli F, Cesana C, Gaini $\mathrm{SM}$, et al: $A P O E$ influences vasospasm and cognition of noncomatose patients with subarachnoid hemorrhage. Neurology 64:1238-1244, 2005

12. Laskowitz DT, Fillit H, Yeung B, Toku K, Vitek MP: Apolipoprotein E-derived peptides reduce CNS inflammation: implications for therapy of neurological disease. Acta Neurol Scand 114 (Suppl 185): 15-20, 2006

13. Laslo AM, Eastwood JD, Chen FX, Lee TY: Dynamic CT perfusion imaging in subarachnoid hemorrhage-related vasospasm. AJNR Am J Neuroradiol 27:624-631, 2006

14. Leung CHS, Poon WS, Yu LM, Wong GKC, Ng HK: Apolipoprotein $\mathrm{E}$ genotype and outcome in aneurysmal subarachnoid hemorrhage. Stroke 33:548-552, 2002

15. Lynch JR, Wang H, Mace B, Leinenweber S, Warner DS, Bennett ER, et al: A novel therapeutic derived from apolipoprotein $\mathrm{E}$ reduces brain inflammation and improves outcome after closed head injury. Exp Neurol 192:109-116, 2005

16. Lynch JR, Wang H, McGirt MJ, Floyd J, Friedman AH, Coon AL, et al: Simvastatin reduces vasospasm after aneurysmal subarachnoid hemorrhage: results of a pilot randomized clinical trial. Stroke 36:2024-2026, 2005

17. McCarron MO, Muir KW, Weir CJ, Dyker AG, Bone I, Nicoll $\mathrm{JAR}$, et al: The apolipoprotein $\mathrm{E} \epsilon 4$ allele and outcome in cerebrovascular disease. Stroke 29:1882-1887, 1998

18. McGirt MJ, Lynch JR, Parra A, Sheng H, Pearlstein RD, Laskowitz DT, et al: Simvastatin increases endothelial nitric oxide synthase and ameliorates cerebral vasospasm resulting from subarachnoid hemorrhage. Stroke 33:2950-2956, 2002

19. McGirt MJ, Woodworth GF, Pradilla G, Legnani F, Warner DS, Tamargo R, et al: Simvastatin attenuates experimental cerebral vasospasm and ameliorates serum markers of neuronal and endothelial injury in patients after subarachnoid hemorrhage: a dose-response effect dependent on endothelial nitric oxide synthase. Clin Neurosurg 52:212-214, 2005

20. Mendelow AD: Pathophysiology of delayed ischaemic dysfunction after subarachnoid haemorrhage: experimental and clinical data. Acta Neurochir Suppl 45:7-10, 1988

21. Nosko M, Weir B, Krueger C, Cook D, Norris S, Overton T, et 


\section{Dissociation between vasospasm and functional improvement}

al: Nimodipine and chronic vasospasm in monkeys: part 1. Clinical and radiological findings. Neurosurgery 16:129-136, 1985

22. Parra A, McGirt MJ, Sheng H, Laskowitz DT, Pearlstein RD, Warner DS: Mouse model of subarachnoid hemorrhage associated cerebral vasospasm: methodological analysis. Neurol Res 24:510-516, 2002

23. Petruk KC, West M, Mohr G, Weir BK, Benoit BG, Gentili F, et al: Nimodipine treatment in poor-grade aneurysm patients. Results of a multicenter double-blind placebo-controlled trial. J Neurosurg 68:505-517, 1988

24. Pickard JD, Murray GD, Illingworth R, Shaw MD, Teasdale GM, Foy PM, et al: Effect of oral nimodipine on cerebral infarction and outcome after subarachnoid hemorrhage: British aneurysm nimodipine trial. BMJ 298:636-642, 1989

25. Teasdale GM, Nicoll JAR, Murray G, Fiddes M: Association of apolipoprotein $\mathrm{E}$ polymorphism with outcome after head injury. Lancet 350: 1069-1071, 1997

26. Yokoo N, Sheng H, Mixco J, Homi HM, Pearlstein RD, Warner
DS: Intraischemic nitrous oxide alters neither neurologic nor histologic outcome: a comparison with dizocilpine. Anesth Analg 99:896-903, 2004

Manuscript received July 28, 2006.

Accepted in final form August 4, 2006.

This work was supported by Grant No. 2R44NS43954 from the National Institutes of Health. Cognosci, Inc., supplied the peptide and the National Cancer Institute provided the CAI. Robert Yates was financially supported by the Sarnoff Cardiovascular Research Foundation.

Address reprint requests to: Daniel T. Laskowitz, M.D., Box 2900, Duke University Medical Center, Durham, North Carolina 27710. email: danl@neuro.duke.edu. 